\title{
Maternidades en cautiverio. Experiencias de maternidad, embarazo y parto en centros clandestinos de detención durante la última dictadura militar argentina
}

\section{Victoria Álvarez}

Universidad de Buenos Aires, Facultad de Filosofía y Letras, Instituto Interdisciplinario de Estudios de Género/Conicet.

\section{(1) Fabricio Laino Sanchis}

Universidad de Buenos Aires, Facultad de Ciencias Sociales, Instituto de Investigaciones Gino Germani-Conicet/UNSAM/UNDAV.

Fecha de recepción: 5 de setiembre de 2016. Fecha de aceptación: 12 de diciembre de 2017.

\section{Resumen}

Durante la última dictadura militar en la Argentina (1976-1983) las mujeres representaron alrededor del 30\% del total de las víctimas del accionar represivo del Estado. Estas detenidas sufrieron un repertorio diverso y específico de violencia por su condición de género. En los centros clandestinos de detención, muchas mujeres que fueron secuestradas embarazadas o junto con sus hijos/as pequeños/as, se vieron sometidas a formas diferenciales de vigilancia, control y violencia sobre sus cuerpos. Gran parte de las mujeres embarazadas que dieron a luz en cautiverio se encuentran desaparecidas y sus hijos/as fueron apropiados/as por personal de las fuerzas armadas y de seguridad. En el presente trabajo nos proponemos reflexionar sobre las experiencias de maternidad en los centros clandestinos de detención durante la última dictadura militar argentina desde una perspectiva de género. Indagaremos en las concepciones sobre la familia, la maternidad y el rol social de las mujeres que subyacían al accionar de los perpetradores de la violencia sobre las detenidas. A partir de testimonios de mujeres sobrevivientes, reconstruiremos las modalidades y dispositivos represivos específicos aplicados a las detenidas embarazadas. Por último, analizaremos los sentidos que en sus memorias asignan las sobrevivientes a sus experiencias de maternidad en cautiverio. 


\begin{abstract}
During the last military dictatorship in Argentina (1976-1983), women accounted for about $30 \%$ of the total number of victims of state repression. These detainees suffered a diverse and specific repertoire of gender-based violence. In this context, many women who were abducted pregnant or with their young children were subjected to differential forms of surveillance, control and violence on their bodies. Most of the pregnant women who gave birth in captivity are disappeared and their children were appropriated by army and security forces members. The present paper aims to think over the experiences of mothering in the clandestine detention centers during the last Argentine military dictatorship from a gender perspective. We will inquire into the conceptions about family, motherhood and the social role of women that underlay the actions of the perpetrators of the violence against those women. Based on the analysis of testimonials from surviving women, we will reconstruct the specific repressive modalities applied to pregnant detainees. Finally, we will analyze the meanings that survivors assign in their memories to their experience of mothering in captivity.

Keywords:

Memories, Testimony, Mothering, Clandestine Detention Centers, Last military dictatorship in

Argentina.
\end{abstract}

\title{
Introducción ${ }^{1}$
}

Durante la última dictadura militar argentina (1976-1983), las fuerzas armadas pusieron en práctica una serie de estrategias y dispositivos represivos, que han sido caracterizados como "terrorismo de Estado" y cuyo rasgo saliente fue el uso ilegal del aparato del Estado en la persecución y el aniquilamiento de las organizaciones políticas y sociales opositoras. Se creó una extensa red de centros clandestinos de detención, la mayoría de ellos ocultos dentro de dependencias oficiales de las fuerzas armadas y de seguridad, donde fueron torturadas, sometidas a violencia sexual y desaparecidas miles de personas que habían sido secuestradas (Calveiro, 1998; Duhalde, 1999 [1983]; Pittaluga, 2010; Águila, 2013).

Las mujeres representaron alrededor del $30 \%$ del total de las víctimas del terrorismo de Estado. Estas detenidas sufrieron un repertorio diverso y específico de violencia represiva por su condición de género. En ese marco, muchas mujeres que fueron secuestradas embarazadas - o junto con sus hijos/as pequeños/as- se vieron sometidas a formas diferenciales de vigilancia, control y violencia sobre sus cuerpos.

En el presente trabajo nos proponemos reflexionar sobre la experiencia de la maternidad en los centros clandestinos de detención desde una perspectiva de género. Las fuentes principales para esta investigación son diversos testimonios de mujeres que fueron secuestradas siendo madres o estando embarazadas y parieron durante su detención o después de su liberación; así como también de mujeres que fueron compañeras de cautiverio de detenidas que dieron a luz en los períodos de sus secuestros y luego fueron desaparecidas.

El corpus analizado se nutre de tres tipos distintos de testimonios. Un primer grupo consiste en entrevistas realizadas por el equipo de investigación y producción del documental Campo de batalla. Cuerpo de mujer (Fernando Álvarez, 2013) ${ }^{2}$ del que for1 Deseamos expresar nuestro profundo agradecimiento a las mujeres que brindaron los testimonios que son la base de este trabajo. También a las/os evaluadoras/es anónimas/os para Mora que nos aportaron valiosos comentarios y reflexiones para mejorar este trabajo. Por último, a llenia Arocha por su colaboración con el relevamiento documental.

2 Campo de batalla, cuerpo de mujer (Fernando Álvarez, 2013), en cuya investigación participamos, es un documental que se propone visibilizar las prácticas de violencia sexual ejercidas sobre mujeres 
mamos parte. Un segundo grupo de testimonios procede de entrevistas realizadas por investigadores/as de la Asociación Civil Memoria Abierta (2001-2007). Por último, dos testimonios fueron extraídos de declaraciones judiciales realizadas por sobrevivientes en el Juicio a las Juntas (1985). Los últimos dos grupos de testimonios fueron relevados en el Archivo Oral de la Asociación Civil Memoria Abierta. ${ }^{3}$

A través de estos testimonios reconstruiremos las características distintivas de la represión sobre estas mujeres y, al mismo tiempo, analizaremos las formas en que la maternidad marcó sus experiencias de cautiverio.

\section{Género y dictadura: concepciones castrenses y violencia sexual en centros clandestinos de detención}

La violencia hacia las mujeres, manifestada de formas muy diversas, aparece de manera repetida a lo largo del tiempo y del espacio en diversos procesos sociales y políticos. No se trata de hechos excepcionales que puedan ser explicados por características patológicas individuales de aquellos que la ejecutan, sino que es un elemento estructuralmente constitutivo de las sociedades patriarcales. Las violencias física, psíquica y simbólica sobre las mujeres actualizan el poder de la dominación masculina y reafirman, de ese modo, las relaciones jerárquicas de género que organizan la vida social. Durante los períodos históricos en los que se imponen regímenes autoritarios, y sobre todo cuando se despliegan dispositivos represivos concentracionarios, la violencia hacia las mujeres tiende a exacerbarse hasta alcanzar dimensiones extremas (Lagarde, 1997; Segato, 2003; Aucía et al., 2011; D’Antonio, 2016).

Como sostiene Aucía, históricamente los conflictos y contextos represivos han tenido (y tienen) una impronta masculina: "son decididos por varones para luchar por intereses que son representados por varones y llevados a cabo fundamentalmente por varones" (Aucía etal., 2011:34). La guerra es una actividad basada en la diferencia de géneros y, más aún, es una actividad generizada y representativa de valores masculinos y experiencias atribuidas a los varones. Si bien en la Argentina no hubo una guerra o un conflicto armado sino terrorismo de Estado, este fue ejecutado por el aparato militar y policial que se apoyaba sobre esas bases ideológicas, y muchas de las categorías de género formaban parte de la lógica del poder represivo y concentracionario. En este sentido, durante la última dictadura militar (1976-1983), los modos en los que las mujeres detenidas fueron tratadas en los centros clandestinos de detención abarcaron formas variadas de agresión, incluyendo repertorios de violencia sexual como metodología de intensificación de la opresión (Bacci et al., 2012). Independientemente de que la mayoría de las organizaciones políticas revolucionarias no tuvieran como objetivo en sus programas la transformación de las relaciones jerárquicas de género, el modelo hegemónico de familia había sido fuertemente tensionado y cuestionado: la presencia de mujeres en todos los frentes de militancia contribuía a un cuestionamiento de hecho del imaginario de lo que era, debía ser y podía hacer una mujer (Oberti, 2015). Estas rupturas encendieron doblemente las alarmas de la política represiva. Para los represores, las mujeres militantes se habían apartado de los roles

detenidas-desaparecidas durante el terrorismo de Estado de la última dictadura militar (1976-1983). Para dicha realización se efectuaron entrevistas a mujeres sobrevivientes de centros clandestinos de detención de distintas provincias del país. La película se filmó entre 2010 y 2013, contó con un subsidio del Instituto Nacional de Cine y Artes Audiovisuales (INCAA) y fue estrenada a principios de 2013. Actualmente, se sigue proyectando en cines, festivales, centros culturales y universidades.

3 Los testimonios analizados fueron prestados durante el período 2001-2017, están grabados en video y duran aproximadamente entre una y cinco horas cada uno. Siguiendo el protocolo de Memoria Abierta, visionamos los testimonios in situ, tomando notas extensivas y transcribiendo pasajes de sus contenidos. 
de género, situación frente a la cual la violencia sexual representaba un instrumento de castigo correctivo. Esta preocupación es relatada muy claramente en el siguiente testimonio de Miriam Lewin, ${ }^{4}$ quien estuvo detenida en el CCD (Centro Clandestino de Detención) Virrey Ceballos ${ }^{5}$ de la Ciudad de Buenos Aires:

En el medio de la tortura me decían "hija de puta”, "puta montonera”, “¿en cuántas orgías estuviste?”, “¿cuántos abortos te hiciste?”. Esta es una cosa que me la repitieron varias veces. “¿En cuántas orgías estuviste?”. Y más aún: “¿Cuántos abortos te hiciste?". Es más, algunas cosas eran exclamaciones que contribuían a desestabilizarme, pero el tema de los abortos me lo preguntaban y hacían un silencio como esperando que yo efectivamente les respondiera. Yo no me había hecho ningún aborto y en realidad no entendía para qué me lo preguntaban. Yo creo que lo de los abortos era como el súmum de la degradación, ¿no? Que eras puta, que te habías acostado con un montón de tipos en orgías y que además te habías hecho varios abortos. Ese era el modelo de mujer militante demonizado que ellos tenían en su cabeza. (Entrevista a Miriam Lewin. realizada con el equipo de investigación de Campo de batalla, cuerpo de mujer, 2012)

Llama la atención el acento que los represores ponían en la posibilidad de la interrupción del embarazo, más aún si tenemos en cuenta que muchas mujeres denunciaron que se les practicaron abortos estando en cautiverio. Podemos suponer que el problema de fondo, entonces, no radicaba en cuántos abortos se había hecho hipotéticamente Miriam Lewin, sino en quién había tomado la decisión sobre los mismos. Los represores, en tanto amos de la vida y de la muerte de sus secuestradas, se consideraban con derecho a decidir que el embarazo de alguna de las detenidas no debía llegar a término. Las detenidas, en cambio, si habían abortado, parecían convertirse en enemigas de la "familia argentina". Así, el testimonio de Miriam Lewin permite entrever la concepción que los perpetradores tenían de las militantes políticas secuestradas: eran mujeres que se apartaban de la moral patriarcal que ellos valoraban, que creían que peligraba y que, por lo tanto, pretendían reforzar.

Las "delincuentes subversivas", señaladas como "madres abandónicas", suponían para los militares el punto cúlmine de la degeneración de la institución familiar. Como ha indicado Filc, en la concepción castrense, la familia, como institución sagrada y natural, unida por la autoridad paterna sobre la madre y los hijos, constituía la célula básica que componía el cuerpo de la nación. La "subversión" era vista por los militares como una enfermedad que buscaba infectar dicho cuerpo corrompiéndolo desde la base, desde el nivel celular, desde el interior de la familia. La obligación del Estado era "curar el tejido social enfermo", ejerciendo su autoridad sobre los "agentes patológicos"; debía usar su autoridad para aniquilar a la "subversión" y preservar a la familia argentina. Salvar a la familia, curar a la Nación: la metáfora organicista y el discurso mesiánico conllevaban la intensificación del castigo sobre las mujeres y, en especial, sobre las madres embarazadas (Filc, 1997; Regueiro, 2013).

Así como los militares justificaban la represión ilegal, la tortura y las desapariciones como parte de una "guerra contra la subversión" en defensa de un "modo de vida occidental y cristiano", también justificaron la apropiación como un acto de salvación de los niños/as del peligro, el abandono y el desamor a los que se exponían con sus

4 Miriam Lewin fue secuestrada el 17 de mayo de 1977, estuvo detenida-desaparecida hasta enero de 1979 en dos centros clandestinos de detención: diez meses y medio en Virrey Ceballos y luego en la Escuela de Mecánica de la Armada. En enero de 1979, fue liberada bajo un régimen de libertad vigilada, que continuó hasta abril de 1981.

5 Virrey Ceballos fue un centro clandestino de detención que funcionó entre 1976 y 1977 en Virrey Cevallos 630, en el barrio de San Cristóbal de la Ciudad de Buenos Aires. Fue una casa operativa de la Fuerza Aérea pero también actuaban allí grupos de tareas (GT) pertenecientes al Ejército y a la Policía Federal. 
madres. En este caso, los militares apelaron a discursos y representaciones sobre las "malas madres" que tenían una larga tradición dentro de la burocracia estatal. A las mujeres embarazadas detenidas-desaparecidas se les aplicaron todos los estigmas sobre los "padres abandónicos" que el campo institucional de la minoridad había desarrollado a lo largo del siglo XX (Villalta, 2012).

Los perpetradores consideraron como la mejor opción la separación de los/as niños/ as de sus madres y padres. No solo porque obtenían un "botín de guerra" muy preciado por muchas familias que tenían dificultades para tener hijos/as, sino también porque supusieron que separarlos/as de sus "malas madres" era la única manera para torcer el destino de esos/as niños/as y convertirlos en "verdaderos argentinos" (Regueiro, 2013).

Muchas de las sobrevivientes narran que las cuestiones sexuales aparecían repetidamente en el discurso y también en la práctica de los torturadores en los centros clandestinos de detención. Las desigualdades de género permearon el funcionamiento de los espacios represivos. En tal sentido, Barrancos sostiene:

Hay una diferencia de género en los atributos de los que se invistió el horror del terrorismo de Estado: las violaciones, las condiciones del parto y el secuestro de recién nacidos aumentaron la victimización de las mujeres. [...] No sostengo, absolutamente, que las mujeres sufrieran más que los varones, sino que les fueron infligidos repertorios más amplios de suplicio. (Barrancos, 2008: 147-148)

En todas las entrevistas que realizamos a mujeres sobrevivientes o que relevamos para este trabajo encontramos un claro interés en dar cuenta de las formas específicas de violencia sexual ${ }^{6}$ [padecidas por ellas o por sus compañeras de cautiverio. Las testimoniantes suelen manifestar un recuerdo muy vívido de la angustia ante estas formas de violencia.

Diferentes trabajos han estudiado las formas de violencia sexual sufridas por las mujeres en los centros clandestinos de detención (Álvarez, 2000, 2015; Sonderéguer, 2012; Bacci et al., 2012). En el presente artículo nos interesa analizar una de las formas distintivas que adoptó la violencia sexual en los espacios concentracionarios: la ejercida sobre mujeres que eran madres o que estaban embarazadas durante su secuestro.

\section{Maternidad y violencia en los centros clandestinos de detención}

$\mathrm{Al}$ analizar la historia reciente desde el presente, llama la atención la enorme cantidad de mujeres militantes que, en el contexto peligroso y precario en el que transcurrían sus días, estaban embarazadas o ya tenían hijos/as pequeños/as. Lo llamativo no es, claro está, que las mujeres tengan hijos/as, sino que se trataba de mujeres muy jóvenes que además habían elegido la militancia como forma de vida. En un momento histórico en que los métodos anticonceptivos habían alcanzado una fuerte inserción cultural y habían influido en la liberación de las costumbres sexuales (Cosse, 2010), el hecho de que se tratase de mujeres en edad reproductiva no implicaba, necesariamente, el embarazo y la maternidad (en particular tratándose de una población de mujeres activas políticamente y, en una proporción importante, provenientes de sectores con recursos económicos y con un nivel de educación medio o superior). Sin embargo,

6 Estas formas generizadas de violencia fueron padecidas especialmente por las mujeres. Sin embargo, no desconocemos que también algunos varones fueron víctimas de aquellas. Podemos suponer que en estos casos se trataba de un intento más por parte de los torturadores de humillar a los detenidos, feminizándolos. 
como ha analizado Oberti, la maternidad se multiplicaba y, en muchos casos, se trataba de una maternidad decidida de manera consciente. Extraer de los cuerpos todo lo que estos pudieran dar era la consigna para aquellos varones y mujeres que estuvieron dispuestos a la maternidad y paternidad con la misma intensidad con la cual se preparaban para entregar su vida por la causa revolucionaria. Lo extremo de la exigencia tiene, sin embargo, diferencias según se trate de cuerpos femeninos o masculinos. La maternidad es una práctica social que presenta una indiscutible marca de género: solo las mujeres pueden parir, por lo tanto para ellas esa parte específica de la procreación, la de gestar y parir, es indelegable (Oberti, 2015).

Las condiciones en las que cientos de mujeres atravesaron el embarazo y la maternidad en cautiverio y el sentido que le otorgaron a esa experiencia han sido escasamente consideradas como formas específicas de violencia contra las mujeres. Dado que a gran parte de las detenidas embarazadas se les sustrajeron sus hijos/as recién nacidos/ as y fueron finalmente asesinadas por las fuerzas represivas, contamos con muy pocos testimonios que puedan dar cuenta de esta situación límite de la experiencia concentracionaria. Podemos reconstruirla parcialmente con el testimonio de compañeros/as de cautiverio que pueden aportar una memoria vicaria, indirecta, de esta experiencia. También existen algunos casos excepcionales de mujeres que sobrevivieron al cautiverio y fueron liberadas con sus hijos/as. En todo caso, si bien este limitado universo de relatos vivenciales no permite realizar generalizaciones, sí nos aporta una vía de acceso a las múltiples formas en las que aquellas mujeres experimentaron y sintieron la maternidad, el embarazo y el parto en cautiverio.

En principio, cabe decir que las mujeres embarazadas en general no estuvieron exentas de las formas de violencia que sufrió el resto de sus compañeros/as de detención. En la mayoría de los casos, las sobrevivientes relatan que ellas, o sus compañeras de cautiverio, esperaron el parto en condiciones infrahumanas y humillantes (Regueiro, 2013). En una entrevista realizada por el equipo del Archivo Oral de Memoria Abierta, Susana Reyes, ${ }^{7}$ sobreviviente del CCD El Vesubio, ${ }^{8}$ narraba:

[...] [Luego de que trasladaran a Osvaldo Mantello, su compañero] ahí trascurrieron en ese mes como siempre, qué sé yo... tuve algunos problemas con algunos guardias, ¿viste? Me pegaron... me llevaban por ahí a limpiar la sala, a la enfermería, que era otra casa, porque son tres casas. Un tipo que me hacía chocar con todos los árboles... después me llevaban a limpiar toda la sangre. Bueno, era una cosa espantosa. Pero por otro lado, se iban fortaleciendo los lazos con mis compañeras, embarazadas quedábamos tres. (Memoria Abierta, testimonio de Susana Reyes, 2003)

\footnotetext{
7 Susana Reyes estuvo desaparecida en el CCD El Vesubio (provincia de Buenos Aires) desde el 16 de junio de 1977 hasta el 16 de septiembre del mismo año. Cuando la secuestraron, estaba embarazada de tres meses. Se había alejado de la militancia en 1975. Su compañero, Osvaldo Mantello, fue secuestrado junto con ella, llevado al mismo campo y permanece desaparecido. El hijo de ambos nació a fin de ese año. Susana es docente de adultos y de chicos en situación de riesgo.

8 El Vesubio fue un centro clandestino de detención ubicado en La Matanza (provincia de Buenos Aires), cerca de la intersección del Camino de Cintura con la autopista Ricchieri, en un predio del Servicio Penitenciario Federal.
} 
Por su parte, Adriana Calvo ${ }^{9}$ relataba de este modo el trato que recibieron en el CCD Comisaría $5^{\mathrm{a}}$ de La Plata Inés Ortega ${ }^{10}$ y ella; ambas con embarazos avanzados, Inés Ortega a punto de parir:

Bergés ${ }^{11}$ nos sacó de la celda a Inés y a mí, ya que estaba yo embarazada, aunque yo no tenía contracciones; nos llevaron prácticamente a la rastra, escaleras arriba, en una escalera de cemento, donde nos golpeábamos en todos los escalones; nos tiró en el piso y en menos de tres minutos nos hizo un tacto a cada una; era sin duda un médico obstetra; dijo que estábamos perfectamente bien y nos volvieron a tirar en la celda; unos días después, comenzó el trabajo de parto de Inés Ortega; yo, que era la mayor, que ya había tenidos dos hijos, me encargué de estar con ella mientras las demás pedían a los gritos ayuda; estuvimos todas gritando al cabo de guardia para que viniera; Inés tenía contracciones cada vez más seguidas, yo trataba de decirle que la respiración abdominal, que el jadeo; estaba tirada en el piso, desesperada; por fin, muchas horas después, comenzó su trabajo de parto por la mañana y vinieron a buscarla muy tarde a la noche, se la llevaron al cuarto de al lado, el mismo que usaban para torturar, la subieron a la mesa y vendada, oíamos sus gritos, oíamos las risas de los guardias, oíamos los gritos del médico y por fin oímos el llanto del bebé. (Testimonio de Adriana Calvo en el Juicio a las Juntas, 1985)

Más adelante retomaremos algunos aspectos del testimonio de Adriana Calvo, pero en principio podemos advertir cómo da cuenta de los malos tratos que recibían las embarazadas. En el caso de Inés Ortega, este maltrato persistió incluso estando ella con trabajo de parto.

Más aún, en muchas ocasiones los represores se ensañaban particularmente en las sesiones de tortura con las detenidas embarazadas, aplicándoles tormentos sobre el abdomen, los genitales y otras zonas del cuerpo comprometidas en la gestación. Así lo cuenta en su testimonio Charo Moreno, ${ }^{12}$ quien estuvo secuestrada en el centro clandestino de detención Puente 12. ${ }^{13}$

9 Adriana Calvo era docente e investigadora de la Facultad de Ciencias Exactas de la Universidad de La Plata y militaba en el gremio, que funcionaba en la semiclandestinidad. Fue secuestrada el 4 de febrero de 1977. Estaba embarazada de seis meses y medio. Luego de su secuestro fue conducida al Pozo de Arana ubicado en calle 137 esquina 640, La Plata, que funcionaba como un centro destinado a la tortura. Permaneció en ese lugar durante siete días y luego fue trasladada a la Comisaría $5^{\text {a }}$ de La Plata. Por último, al CCD Pozo de Banfield (sito en la Brigada de Investigaciones de Banfield) ubicado en la intersección de las calles Siciliano y Vernet (provincia de Buenos Aires). El 28 de abril de 1977, poco después de haber dado a luz, fue liberada.

10 Inés Ortega era obrera textil, estudiante secundaria y militante de la Unión de Estudiantes Secundarios (UES). Fue secuestrada junto con su compañero Rubén Leonardo Fosatti en la localidad de Quilmes (provincia de Buenos Aires), donde vivían, el 21 de enero de 1977. Tenía 16 años. Estaba embarazada de siete meses al momento de su secuestro. Ambos fueron vistos en la Comisaría $5^{\circ}$ de La Plata y en el CCD Pozo de Arana. La joven también fue vista en la Brigada de Investigaciones de La Plata. Por testimonios de sobrevivientes pudo saberse que el 12 de marzo de 1977 Inés dio a luz un varón al que llamó Leonardo en la cocina de la Comisaría 5 a. El parto fue asistido por el médico policial Jorge Antonio Bergés. La joven pudo compartir con su hijo menos de cinco días hasta que los guardias le anunciaron que "El Coronel" quería conocerlo y que se lo entregaría a su familia biológica. Su hijo fue recuperado con su verdadera identidad el 11 de agosto de 2005.

11 Jorge Antonio Bergés fue un médico de la Policía de la Provincia de Buenos Aires. Era responsable de los partos de las secuestradas embarazadas en diferentes centros clandestinos de detención del denominado "Circuito Camps".

12 Charo Moreno fue secuestrada el 4 de noviembre de 1975 en la Ciudad de Buenos Aires, a los 18 años. Permaneció secuestrada aproximadamente 10012 días en el centro clandestino de detención conocido con el nombre de Puente 12 o Protobanco hasta que fue trasladada al penal de Olmos (provincia de Buenos Aires), cárcel en la que su detención fue oficializada. Su hijo Andrés nació allí en 1976. Por último, fue trasladada a la cárcel de Devoto (Ciudad de Buenos Aires), donde permaneció hasta que recuperó su libertad en agosto de 1984, nueve años después de su secuestro.

13 El centro clandestino de detención Puente 12 o Protobanco, dependiente del primer cuerpo del Ejército, funcionó entre 1975 y febrero de 1977 en la provincia de Buenos Aires. Estaba situado enfrente de otro centro clandestino de detención y torturas, conocido como El Vesubio. 
Bueno, yo estaba embarazada de unos 3 meses, casi 4 , y en esa cosa que una tiene, la desesperación de proteger, digo: “icuidado, cuidado que estoy embarazada!”. Es lo primero que se te ocurre decir, ipero qué ridiculez! ¿no? No iban a tener cuidado... Creo que eso fue peor además porque la respuesta era "Ah, ¿sí?". Y ahí había como... Hubo un ensañamiento en un momento muy particular que a mí me dieron por ejemplo, golpes que era una de las formas de tortura, y eran golpes en la panza, especialmente, diciéndome " ¿vos te crees que vamos a dejar que nazca un guerrillerito más?" (Entrevista a Charo Moreno realizada con el equipo de investigación de Campo de batalla, cuerpo de mujer, 2012)

En el testimonio de Charo Moreno pueden vislumbrarse los sentidos detrás de este encarnizamiento. El terrorismo de Estado se proponía ante todo la aniquilación de una alteridad radical, un elemento exógeno al cuerpo social ya previamente definido, delimitado, cercado: el "enemigo interno", la "subversión internacional" (Franco, 2012). Los centros clandestinos de detención fueron el eje espacial e institucional alrededor del cual giró este exterminio. Pero para aniquilar a ese otro absoluto no bastaba con secuestrar y asesinar a los/as militantes y desarticular sus organizaciones: había que hacer algo con su descendencia. Es frecuente que en declaraciones posteriores los represores afirmaran, como señaló en una ocasión Ramón Camps - ex jefe de la Policía de la Provincia de Buenos Aires y que tuvo bajo su dirección varios centros clandestinos de detención-que "los padres subversivos educan a sus hijos para la subversión. Eso hay que impedirlo" (Nosiglia, 1985: 17). Con este argumento, la mayoría de los/as niños/as nacidos/as en cautiverio fueron separados/as de sus madres y apropiados/as por agentes de la represión u otras personas allegadas.

Así, en los centros clandestinos de detención las mujeres embarazadas, además de sufrir las formas de violencia sexual que padecieron muchas mujeres (como la desnudez forzada, los manoseos y/o las violaciones), fueron sometidas a un repertorio de dispositivos y prácticas represivas especiales. Ante todo, por el interés de los represores por sus hijos/as por nacer. Con este fin, dentro de los mismos espacios concentracionarios los perpetradores crearon verdaderas "maternidades" clandestinas. Las características de estas "maternidades" fueron descriptas por los y las sobrevivientes en distintos testimonios. Por ejemplo, Alicia Carminati ${ }^{14}$ relataba así las condiciones en las que Stella Montesano ${ }^{15}$ transitó el embarazo y el parto en el CCD Pozo de Banfield:

Stella da a luz en el Pozo de Banfield. Stella estaba, primero, del otro lado, no del lado en que yo estaba. (...) El día que Stella empieza con contracciones, entonces, todos empezamos a golpear. Suben y la bajan a Stella... Ahora, después de todos los relatos y de la gente que estuvo en Banfield, se sabe que la llevaron a una dependencia en la planta baja y ahí tuvo familia. Y nació Martín, que es como Stella y Jorge lo llamaron, el 5 de diciembre del 76 . Prácticamente después de diez días, Stella vuelve a la planta alta que es donde estaban estas celdas. Jorge siempre estuvo de nuestro lado en la parte de atrás, yo estaba en la primera celda y es ahí cuando estamos juntas. Y es cuando Stella me relata (...) primero de todo, que había tenido un varón. Que había sido asistida por un partero varón o médico,

14 Alicia Carminati fue secuestrada el 24 de septiembre de 1976 en el domicilio de un familiar en La Plata. Estuvo detenida-desaparecida hasta el 28 de diciembre de ese mismo año en los centros clandestinos de detención Arana y Pozo de Banfield. En 1983, se radicó en Australia, donde residía al momento de la entrevista.

15 Stella Maris Montesano, junto con Jorge Ogando (su compañero) militaban en el PRT-ERP. Ambos fueron secuestrados el 16 de octubre de 1976 en su domicilio de La Plata. La joven estaba embarazada de ocho meses. Jorge fue visto en el CCD Pozo de Banfield. Según testimonios de sobrevivientes, Stella Maris permaneció detenida en ese CCD donde dio a luz un niño al que llamó Martín el 5 de diciembre de 1976. Después del parto fue llevada al CCD Pozo de Quilmes, donde fue vista por última vez. Stella y Jorge permanecen desaparecidos. Martín Ogando Montesano (su hijo) recuperó su verdadera identidad el 5 de noviembre de 2015 . 
en ese momento no sabíamos quién era. Ahora sabemos que fue Bergés (...) A Stella cuando la separan del bebé, le prometen que se lo iban a entregar a la familia, lo que por supuesto no sucedió. (Memoria Abierta, testimonio de Alicia Carminati, 2006)

Este relato describe muy bien las características que, con particularidades específicas a cada centro clandestino de detención, tuvieron las "maternidades" clandestinas. Se trataba de espacios específicos donde las mujeres embarazadas eran recluidas durante la gestación hasta que daban a luz a sus hijos/as (en algunos casos, incluso hasta días o semanas después del parto, en general hasta que eran "trasladadas", eufemismo de los represores para referirse al asesinato de los secuestrados/as). Estos espacios, con sus actores, sus tiempos y sus rutinas específicas, perseguían el objetivo de lograr el mayor control posible sobre el cuerpo de las mujeres y sus futuros/as hijos/as. Allí los represores podían vigilar sus embarazos y controlar los nacimientos que, en muchos casos, se programaban para ser realizados por cesáreas. También se garantizaba el aislamiento de las mujeres, para desactivar así cualquier forma potencial de solidaridad de los/as demás detenidos/as y minimizar la circulación de información sobre el destino final de los/as niños/as, mientras que a las madres, por lo general, se les decía que los bebés serían entregados a sus familias. Estas "maternidades" solían contar con la presencia regular de uno o más médicos para seguir la evolución de los embarazos. De esta manera, los represores producían una instrumentalización radical de los cuerpos femeninos: las detenidas, sometidas al poder deshumanizante del centro clandestino de detención, lejos de poder decidir sobre sus maternidades, quedaban reducidas únicamente a sus funciones reproductivas (Calveiro, 1998; Álvarez, 2000; Regueiro, 2013).

En algunos casos, los nacimientos no se efectuaron en los centros clandestinos de detención sino en hospitales y centros de salud. En estas ocasiones, las detenidas parieron en unidades hospitalarias acondicionadas a esos efectos, donde contaron con la asistencia no solo de médicos sino también de enfermeras/os, parteras/os, camilleroas/os, monjas y otros/as actores que circulaban en esas instituciones (Álvarez, 2000; Regueiro, 2013). Nuevamente, el testimonio de Adriana Calvo permite reconstruir una de estas situaciones, la del parto de Silvia Mabel Isabella Valenzi, ${ }^{16}$ con quien compartió el cautiverio en el CCD Pozo de Banfield:

Estaba una chica, de la cual yo por muchos años no recordé su nombre, me acordaba el apodo, le decían “La Gata”, era muy bonita, rubia y ella me contó su parto y yo realmente pensé, pensé que se había vuelto loca, porque después de haber visto el parto de Inés Ortega, de haberlo oído, después de haber vivido mi parto, después que me habían contado el parto de María Eloísa Castellini, ${ }^{17}$ lo que esta chica me contaba me parecía increíble. Esta chica me contó que había estado

16 Silvia Mabel Isabella Valenzi fue secuestrada el 22 de diciembre de 1976 en la ciudad de La Plata. Cuatro días antes, el 18 de diciembre, había sido secuestrado Carlos Alberto López Mateos (su compañero) mientras se encontraba en el Parque Saavedra de La Plata. Silvia estaba embarazada de cuatro meses. Por testimonios de sobrevivientes, pudo saberse que la joven permaneció detenida en la Comisaría $5^{\text {a }}$ de La Plata y en el CCD Pozo de Quilmes. Según pudo relatar una enfermera, la joven fue llevada al Hospital de Quilmes para tener a su hija y el 2 de abril de 1977 tuvo una niña a la que llamó Rosa. Por testimonios pudo saberse que luego de dar a luz fue llevada al CCD Pozo de Banfield. Durante su cautiverio la llamaban “La Gata”. Silvia y Oscar permanecen desaparecidos y aún no se ha dado con el paradero de su hija.

17 María Eloísa Castellini fue secuestrada el 11 de noviembre de 1976 en Merlo (provincia de Buenos Aires). Estaba embarazada de tres o cuatro meses. Constantino Petrakos (su compañero) logró salir del país y refugiarse en Europa, desde donde manifestó a sus familiares que volvería al país. A partir de noviembre o diciembre de 1977 se perdió su rastro. Por testimonios de sobrevivientes se supo que entre el 8 y el 12 de abril de 1977, María Eloísa dio a luz una niña en el CCD Pozo de Banfield a la que llamó Victoria. Anteriormente, fue vista en el CCD denominado Protobanco y, posiblemente, haya pasado por la Brigada de Investigaciones de San Justo. María Eloísa y Constantino permanecen desaparecidos y aún no se ha dado con el paradero de su hija. 
secuestrada en el Pozo de Quilmes, así lo llamaba ella, que la habían llevado en el momento del parto al hospital de Quilmes, que la habían internado en el hospital de Quilmes, y que había tenido su criatura en una cama de un hospital municipal y que la habían atendido una partera, y una enfermera, y que ella le había dado a la partera y a la enfermera su nombre y el teléfono, no sé si la dirección, la forma de comunicarse con su madre y que ella tenía la esperanza de que le hubieran avisado, me dijo que había tenido una mujer, y yo no le creí, no podía creer que fuera verdad y que después le habían quitado la nena y que la habían llevado allí. Muchos años después me enteré que "La Gata" era Silvia Mabel Isabella Valenzi, y que toda esta historia era verdad. (Testimonio de Adriana Calvo en el Juicio a las Juntas, 1985)

La incredulidad que en un principio experimentó Adriana Calvo sobre las condiciones en las que se dio el parto de Silvia Valenzi da cuenta de la diversidad de modalidades represivas que existieron para las embarazadas en los distintos centros clandestinos de detención.

Como señalábamos anteriormente, la gran mayoría de los/as niños/as nacidos/as en cautiverio fueron apropiados/as por personal de las fuerzas armadas y de seguridad. Solo en algunos casos excepcionales fueron dejados/as con sus madres o entregados/ as a sus familias de origen. Si bien la apropiación de niños/as nacidos/as en cautiverio fue una práctica cometida de manera sistemática, cada caso tuvo sus características singulares vinculadas, entre otras cuestiones, al perfil de los perpetradores y de las víctimas (adultas y niños/as), las condiciones en las que se produjo el secuestro y la dinámica de funcionamiento de cada centro clandestino de detención (Villalta, 2012; Regueiro, 2013).

En la mayoría de los casos, la consumación legal de la apropiación fue el mecanismo de la inscripción falsa, por el cual los apropiadores lograban inscribir como hijos/as propios/as a los/as niños/as apropiados/as gracias a certificados médicos fraguados. Estas inscripciones pudieron multiplicarse porque el mecanismo, aunque ilegal, era una práctica absolutamente habitual dentro de la burocracia estatal (Villalta, 2012).

\section{Sentidos y memorias de las experiencias de maternidad en cautiverio}

Domínguez señala que "la maternidad tiene leyes propias, una materialidad propia, un régimen, un poder y una economía propios" (2007: 39). Estas leyes implican un "trabajo de transformación de los cuerpos" de ambos, madres e hijos/as, que excede "la capacidad fecundante" y tiene lugar en la "capacidad sentimental específica que se despliega difusa, potente y soberana, sobre los cuerpos y las vidas de los hijos en las diferentes etapas" (ibídem: 40). Esta experiencia tan movilizadora se vio drásticamente afectada por el secuestro y marcó fuertemente las vivencias de las mujeres detenidas desaparecidas. En una entrevista que le realizamos junto con el equipo de investigación de Campo de batalla, cuerpo de mujer, Isabel Cerruti ${ }^{18}$ narraba:

A mí me habían secuestrado con mi hijo de once meses, recuerdo que cuando me subieron al auto me lo querían sacar, yo me agarré a él, igualmente si al bebé 18 Isabel Cerruti fue militante estudiantil de la organización Montoneros en la universidad y es profesora de historia. Fue secuestrada el 22 de julio de 1978, permaneció detenida-desaparecida en el CCD el Banco (provincia de Buenos Aires), junto con su hijo de once meses hasta el 26 de agosto, momento en el que la trasladaron al Olimpo en el barrio de Floresta de la Ciudad de Buenos Aires, donde permaneció secuestrada hasta el 28 de enero de 1979. Su pareja, Ernesto Berner (el padre de su hijo) está desaparecido desde el $1^{\circ}$ de enero de 1977. 
me lo hubieran querido sacar, me lo hubieran sacado, pero me lo dejaron tener. Cuando llegamos al Banco, en la puerta entro y ahí sí me lo sacan [...] me dicen que me quede tranquila, que con los chicos no se metían y con las mujeres tampoco, esto yo lo entendí como que no iban a hacerle nada a mi hijo y que a mí no me iban a violar. Eso es lo que yo entendí en ese momento. Yo no sabía qué iba a pasar, luego supimos de las apropiaciones, yo pensé que en ese momento lo iban a llevar a un orfanato o que lo iban a dejar en la calle. Lo que pasó con mi hijo, a las horas, fue que bueno, yo lo escuchaba llorar todo el tiempo [...] A la noche vinieron y me dijeron que escribiera en un papel la dirección de donde quería que llevaran a mi hijo, anoté la dirección de mis padres, me trajeron a Norbert, a Norberto que era mi hijo, y me dijeron "despedite que se lo llevamos". Y bueno, fue uno de los momentos más terribles de mi vida.

[...] Yo estaba en la celda y lloraba, ya me habían picaneado, y más allá del dolor físico yo lloraba y me daba cuenta que había pasos [... y al rato se abrió la puerta y él me preguntó qué estaba pasando y yo le dije la verdad: que yo estaba llorando porque había pasado con mi hijo esto y que no sabía dónde estaba. [...] entonces me pidió el número de teléfono de mis padres y vino luego y me dijo "no atiende nadie en tu casa", yo dije "bueno, otra mentira". Al rato me lleva a hablar por teléfono, marca el teléfono, no hay nadie en mi casa, y así 405 cinco veces y a eso de las 3 de la mañana viene y arrastrándome me lleva y me dice "hablá" y me da con mi mamá [...] Y con mucho miedo le pregunto por Norberto, con la seguridad absoluta de que ella me iba a decir "no sé”, y me dice "está durmiendo". Entonces cuando me dice eso le digo "bueno, mandale un beso, tranquila, estoy bien", yo creo que ella intuía que nos estaban escuchando, así que nos saludamos y cortamos y yo le dije al guardia "bueno ahora me pueden matar, ya está, mi hijo está vivo”. (Entrevista a Isabel Cerruti realizada con el equipo de investigación de Campo de batalla, cuerpo de mujer, 2012)

La soledad, el desamparo y la desesperación son las expresiones que mejor definen los sentimientos que aparecen en su relato. A lo largo de su testimonio, Isabel Cerruti menciona en reiteradas ocasiones que lo que más le preocupaba era la separación de su hijo de once meses. La preocupación por el destino del hijo, el temor y la incertidumbre acerca de lo que pudieran hacer con él, el intento de defenderlo, aun en las condiciones de sometimiento del cautiverio, y la ponderación de la vida del hijo por sobre la propia son indicadores de la angustia producida por el secuestro y separación de su hijo así como de un profundo sentido de responsabilidad por su vida. Cabe mencionar que, como pasaba también en otros casos, el padre del niño había desaparecido antes de que él naciera.

Otras mujeres cuyos/as hijos/as quedaron en un paradero incierto o bien que fueron secuestradas con ellos/as, manifiestan en sus relatos haber experimentado similares sentimientos de angustia y de responsabilidad por su destino. Así lo vivió, por ejemplo, Adriana Calvo, que el 4 de febrero de 1977 fue secuestrada de su casa en La Plata, donde se encontraba con su hijo menor, de un año y medio:

Mi preocupación era mirar hacia atrás para ver qué hacían con mi hijo, mi hijo venía con ellos, lo traía uno y lloraba, por supuesto, y vi que se lo entregaban a un vecino (...) en un momento yo pedí por favor que le avisaran a mi marido que yo estaba allí, les dije que mi marido estaba trabajando en la Universidad, que le avisaran para que fuera a recoger a mi hijo (...). Allí yo me enteré de que mi marido también estaba secuestrado. (Testimonio de Adriana Calvo en el Juicio a las Juntas, 1985) 
Una preocupación similar aparece en el testimonio de Delia Bisutti, ${ }^{19}$ que fue secuestrada y detenida dos veces en el CCD Sheraton:

Yo pensaba mucho en mi hijo, sin saber si después de que nos habíamos separado ahí, mi marido y mi hijo estaban bien o no, no lo sabía. Si con los datos que tenían, si los podían llegar a ir a buscar a otro lado. (Memoria Abierta, testimonio de Delia Bisutti, 2001)

A partir de estos testimonios podemos ver que, a pesar de las particularidades de cada centro clandestino, la separación de sus hijos/as, el sentimiento de responsabilidad por ellos/as y la incertidumbre sobre su destino marcaron muy fuertemente la experiencia de muchas de las mujeres detenidas que ya eran madres. El secuestró limitó sus experiencias de maternidad y, a la vez, la maternidad marcó sus experiencias concentracionarias.

También las detenidas embarazadas vivieron con temor las consecuencias de las torturas en el desarrollo de sus embarazos y lo que los represores pudieran llegar a hacer con sus hijos/as cuando nacieran. Dado que, como mencionamos, la mayoría de estas mujeres fueron asesinadas por los perpetradores, son pocos (y por ello, extremadamente valiosos) los testimonios directos que reponen el miedo experimentado ante estas prefiguraciones. Uno de ellos es el de Delia Bisutti, que durante el primero de sus secuestros estaba embarazada de seis meses:

Y pensaba, bueno, que yo además tenía un embarazo de seis meses e intentar, dentro del marco de lo posible, cuidarme desde lo psicológico y lo corporal, dentro de lo que yo podía, ¿no? Que era muy limitado (...)

[Su hija] nació con microcefalia, que significa no crecimiento de las células cerebrales. (...) ¡Fue muy duro! Porque te imaginás que más allá de tener un parto sin el padre, no es un tema sencillo... Y que el parto sea como fue, primero que fue por cesárea, no fue parto común. La nena se adelantó, se adelantó bastante tiempo y bueno... nació con estas deficiencias. Hay una alta probabilidad de que haya sido producto de mi primera desaparición, a raíz del estrés vivido (...) las probabilidades mayores daban que podía tener que ver mucho con los días de encierro de esa etapa del embarazo. Así que bueno, nace María Eva con parálisis cerebral y con problemas físicos, donde no crece, no llegó a crecer... a sentarse, a pararse, a hablar. Todo un desarrollo de bebé sin lograr funciones, digamos. Así que fueron años muy duros. (Memoria Abierta, testimonio de Delia Bisutti, 2001)

A partir de este testimonio podemos deducir cómo su secuestro y el de su marido afectaron profundamente su experiencia de maternidad. Las marcas del cautiverio no se agotaron tras su liberación, ya que no solo su compañero continuó desaparecido, sino que su hija nació con severos problemas de desarrollo (muy probablemente como consecuencia de su paso por el centro clandestino de detención) y falleció a los diez años.

Otro caso que merece ser mencionado es el de Elena Alfaro, ${ }^{20}$ quien estuvo secuestrada en el CCD El Vesubio y fue liberada (sin su pareja, que permanece desaparecido)

19 Delia Bisutti es docente. En el momento de la entrevista, era legisladora de la Ciudad de Buenos Aires. Posteriormente, fue electa diputada nacional por el mismo distrito. Estuvo detenida-desaparecida dos veces en el CCD Sheraton (Comisaría de Villa Insuperable, provincia de Buenos Aires). Su primera detención se produjo el 9 de enero de 1977 y la segunda el 22 agosto del mismo año. Su esposo, Marcelo Castello, está desaparecido desde el 4 de febrero de 1977. Delia fue Secretaria General de la Unión de Trabajadores de la Educación de la Ciudad de Buenos Aires entre 1998 y 2000.

20 Elena Alfaro fue secuestrada el 19 de abril de 1977, permaneció detenida-desaparecida en el CCD El Vesubio (provincia de Buenos Aires) hasta noviembre del mismo año; luego estuvo bajo el régimen 
poco antes de parir. Una vez que nació su hijo, estando ella en "libertad vigilada", se vio obligada a bautizarlo y a designar como padrino al represor que controlaba su libertad vigilada, lo que debe ser pensado en el marco de la arenga moralizante con la que se insistía a los/as liberados/as. El cautiverio siguió signando la experiencia de maternidad de Elena Alfaro una vez afuera del centro clandestino. ${ }^{21}$

Por su parte, Marta Álvarez, ${ }^{22}$ sobreviviente de la ESMA, ${ }^{23}$ rememoraba de esta forma la preocupación por la separación de su hijo nacido en cautiverio:

No teníamos claro qué pasaba con los bebés. A todos les decían que se lo iban a llevar a la mamá. Cuando a Fede se lo llevan a mí me dicen "se lo vamos a llevar a tu mamá". Entonces yo no estaba tranquila de eso, pensé que no, no sabía que habían hecho con el chico. Me pongo mal, mal, mal, insisto y uno de los marinos me dice "bueno, vení, hablá por teléfono". Entonces llamo a casa y mi mamá me dice "Tranquila el nene está acá". Ella sola, le digo "hola, mamá" y me dice "tranquila el nene está acá”. Y cortaron. Ahí sí me quedé tranquila. (Memoria Abierta, testimonio de Marta Álvarez, 2007)

Susana Reyes también estuvo embarazada en cautiverio. En su caso, ella fue liberada poco antes de parir. En la entrevista que citamos más arriba, ella daba cuenta de su experiencia del siguiente modo:

Y... el embarazo lo llevaba bien... digamos, era mi modo de pasar porque... al tener, aparte, varios sentidos anulados, no solo la vista, sino que a veces no querés ni escuchar. Como que tratás de evadirte. Digamos que la relación con mi panza era muy intensa [...] Pero después había un guardia que se llama Chenes, le decían "El polaco" [...] Él siempre me traía algo. Entonces él, cuando por ahí me traía una mandarina, me decía "Bueno, cuidalo, porque ese va a ser para mí". Él me traía esas cosas, porque el nene iba a ser para él, decía él. Yo pensé que era una joda, qué sé yo. [...] Después, cuando a Rosita la traen sin su panza, cuando la llevan a parir, es que yo me di cuenta que era muy posible de que el Polaco estuviera diciéndome la verdad, que el nene iba a ser para él.

Y ya te digo que después, a principios de septiembre, cuando a Rosita la llevan a parir, ya ahí cambió todo. Si hasta ese momento, desde que se fue Osvaldo (se refiere al "traslado" de su compañero), yo te decía que el humor y el amor entre las compañeras te permiten vivir. Después de lo de Rosita... es como que ahí ya no... era imposible seguir. Yo creo que ahí caí en la cuenta de lo monstruoso que era eso, ¿no? Que no era así como pensábamos, que nos iban a matar, que se iban a quedar con mi bebé como se habían quedado con el de ella. Eso fue muy duro para todos. Yo creo que después de ahí, no solo yo estuve mal y tirada y sin querer hacer nada, sino todas las demás. Nadie quiso... como que se cortó el clima ino? la cosa de poder por a hí reírnos de la situación. Cuando

de libertad vigilada hasta su exilio en 1980.

21 Cfr. testimonio de Elena Alfaro en el Juicio a las Juntas (1985).

22 Marta Álvarez fue militante social y política. En junio de 1976 fue secuestrada por un grupo de tareas y llevada al centro clandestino de detención de la ESMA donde permaneció hasta 1979. Durante su cautiverio integró - junto con otros detenidos- el grupo conocido como mini staff. Su pareja, quien fue secuestrado junto con ella, continúa desaparecido. En el momento del secuestro, estaba embarazada. Su hijo mayor, Federico, nació en el Hospital Naval estando ella cautiva en la ESMA.

23 En el casino de oficiales de la Escuela de Mecánica de la Armada (ESMA) funcionó durante la última dictadura militar, entre los años 1976 y 1983, un centro clandestino de detención, tortura y exterminio (CCD), dependiente de la Marina, donde se mantuvo en cautiverio a alrededor de cinco mil personas que fueron secuestradas por las fuerzas armadas y de seguridad. El predio donde tenía su sede la ESMA está ubicado en la zona norte de la Ciudad de Buenos Aires, en el barrio de Núñez, sobre la avenida del Libertador al 8200 y ocupa 17 hectáreas. Allí funcionaron también el Liceo Naval Almirante Brown, la Escuela de Guerra Naval, la Dirección de Educación Naval, la Escuela Nacional de Náutica y la Escuela Nacional Fluvial. 
la sacan a Rosita, que la nombran por su letra. Ella se iba reentusiasmada. Estaba bien, no estaba con dolores de parto, pero... ya nos habían dicho que por ahí le hacían cesárea, que no esperaban porque la iban a llevar a un hospital... Y ella decía que seguro que al compañero, Horacio, lo iban a llevar también para que viera al bebé. Y bueno, todas esperamos que volviera. Y cuando volvió sin la panza y dijo que ni había visto lo que tuvo. O sea que ni le dijeron, ni le mostraron... Ahí nos dimos cuenta que ya está, que no... En un momento ella dijo, bueno... capaz que se lo dieron a mi mamá. O sea que siempre hay una esperanza, o te querés conformar con algo, pero no. No fue así, porque yo después averigüé y todo y ese bebé no apareció [...] Y Rosita tampoco. Ni ella ni el marido, ella tenía dos hijos más, chiquititos [...]. (Memoria Abierta, testimonio de Susana Reyes, 2003)

Citamos de forma extensa este testimonio porque nos permite ver las múltiples dimensiones de la experiencia de la maternidad en cautiverio. En el relato de Susana Reyes observamos nuevamente los sentimientos de soledad, desprotección y una angustia casi imposible de vencer. Al igual que Isabel Cerruti, ella había dejado de ver a su compañero y, si bien no tenía la certeza de su muerte, esta era una posibilidad para ambas. Habían sido maltratadas, torturadas, habían visto morir a compañeros/as de cautiverio, pero la posibilidad de la pérdida del hijo/a aparece en sus relatos como lo más difícil de soportar. Más adelante, en su relato, Susana Reyes narra que tenía un sueño recurrente en el que su madre se presentaba en el centro clandestino de detención y la buscaba para llevársela. Evidentemente, la sensación de desprotección fue muy intensa y lo fue especialmente para aquellas detenidas-desaparecidas que iban a parir en cautiverio, solas, alejadas de sus parejas y de sus familias.

En su relato, Susana Reyes rememora una experiencia escindida en dos tiempos, delimitados por el parto de Rosita, su compañera de cautiverio, que significó la certeza de que la apropiación de su hijo no era una simple broma del guardia sino una posibilidad real. A partir de ese momento, su experiencia se vio marcada por la angustia y la pérdida de toda esperanza, a tal punto que la fuga o la muerte se presentaban como las únicas alternativas posibles: "había pensado, que cuando estuviera más cerca del parto, irme. Abrir la puerta y que sea lo que sea. O sea no me importaba, si me mandaban a la cárcel, si me mataban o me soltaban. Era una indiferencia absoluta". (Memoria Abierta, testimonio de Susana Reyes, 2003)

Sin embargo, también podemos ver que, antes de este momento que ella reconoce como un quiebre, la maternidad fue vivida de una manera muy particular: ella recuerda que, al no poder ver y en muchos casos, no querer escuchar, sentía su "panza" con mucha intensidad. Según relata, el embarazo, al menos durante el primer momento de su experiencia, le habría ayudado a sobrellevar las condiciones extremas del cautiverio. Este relato guarda similitudes con el de Ana María Careaga ${ }^{724}$ que, estando embarazada, estuvo secuestrada en el CCD Club Atlético:25

En el momento en que me tenían atada boca abajo me preguntaron si estaba embarazada. Yo en ese momento, muchas veces me preguntaron por qué dije que no, yo en ese momento dije que no, que no estaba embarazada porque me pareció que era la forma de preservar a mi bebé, a la criatura, y bueno, después al día siguiente cuando estaba internada, en una de las veces que estaba internada

24 Ana María Careaga fue secuestrada el 13 de junio de 1977, con 16 años, embarazada de tres meses. Permaneció detenida en el centro clandestino de detención conocido con el nombre de El Atlético hasta diciembre de ese año.

25 El Club Atlético, El Atlético o El club fue un centro clandestino de detención y tortura que funcionó desde mediados de 1976 hasta diciembre de 1977 en la ciudad de Buenos Aires. Estaba ubicado en un predio situado entre las calles Paseo Colón, San Juan, Cochabamba y Azopardo, en el barrio de San Telmo, donde tenía su sede el Servicio de Aprovisionamiento y los Talleres de la División Administrativa de la Policía Federal. 
en enfermería, dije que estaba embarazada, y digamos, mi embarazo era de menos de tres meses. Durante mucho tiempo no supe qué había pasado, en realidad yo pensé que había perdido el bebé. Si yo tengo que pensar mi experiencia en el campo de concentración vinculada a una cuestión de género o a mi condición femenina, lo más directo vinculado a eso fue el embarazo, para mí haber estado embarazada en el campo de concentración fue algo totalmente distinto, fue algo que me marcó como experiencia, porque estuve casi cuatro meses secuestrada y todo el tiempo que estuve, estuve con los ojos vendados y con cadenas en los pies, atada [...]. Y para mí lo que significó de alguna manera el embarazo fue haber vencido esa impotencia, esa imposibilidad de defenderse, eso que era todo muerte, porque era como transitar por la muerte, porque había un lugar por donde no habían podido llegar. O sea yo cuando estaba un día acostada en la celda con los ojos vendados, de repente se empezó a mover mi hija. Y eso para mí fue increíble. Fue como la vida en el medio de la muerte, fue como sentir que había un lugar al que no habían podido llegar y paradójicamente yo digo que era un privilegio, es difícil pensarlo así, ¿no? Porque un embarazo en estas condiciones... pero fue así para mí, no estaba sola.

Cuando después salí del campo de concentración escribí un poema en donde yo digo "mi sangre fue tu vida, tu sangre fue mi fuerza", porque, bueno cuando llegué a Suecia [...] y me refugié [...] lo que me decían los médicos es que ella [su hija] había podido sobrevivir porque me había chupado a mí toda la sangre, yo estaba completamente anémica, y entonces para mí fue eso, fue como decir, bueno, "mi sangre fue tu vida, tu sangre fue mi fuerza", es decir, yo le salvé la vida a ella, y ella me la salvó a mí, de alguna manera. (Entrevista a Ana María Careaga realizada con el equipo de investigación de Campo de batalla, cuerpo de mujer, 2011)

Ana María Careaga al momento de ser secuestrada tenía 16 años. Su desgarrador relato señala, al igual que los de las otras sobrevivientes citadas, que para ella la experiencia de la maternidad fue algo que marcó radicalmente su cautiverio, "fue algo totalmente distinto". Sin embargo, ella lo recuerda como un "privilegio", como "la vida en medio de la muerte". En el testimonio que citamos más arriba, Susana Reyes comentaba que había tenido una sensación similar al principio, hasta que supo de la posibilidad de que le sustrajeran a su hijo. Ana María Careaga había estado separada del resto de los/as secuestrados/as, por lo que probablemente no conociera aquella posibilidad. Así, para ella el embarazo significó un "triunfo" y una "compañía". Su hija era el último resquicio de humanidad en medio del horror, el único lugar que escapaba a la voluntad deshumanizante del poder concentracionario, "un lugar al que no habían podido llegar". Una vez liberada, al reflexionar sobre su secuestro, llegó a considerar que esa "compañía" era lo que le(s) había permitido sobrevivir: "yo le salvé la vida a ella, y ella me la salvó a mín.

A pesar del contexto de sujeción extrema del centro clandestino de detención, muchos/ as detenidos/as-desaparecidos/as generaron vínculos de solidaridad y un tipo de sociabilidad que, de alguna manera, les permitió sostener su integridad como personas y ejercer algún tipo de resistencia al poder deshumanizante. Estas diversas formas de resistencia ocupan un lugar importante en los testimonios de las sobrevivientes.

Por supuesto, estas manifestaciones se daban en los ínfimos intersticios de un poder que, como hemos visto, buscaba el control total sobre los/as secuestrados/as. El destino de las mujeres, como el de los otros detenidos, siempre estuvo en manos de la voluntad de los represores. En el caso particular de las mujeres embarazadas, como ya hemos señalado, muy pocas sobrevivieron. Las que lo lograron, debieron su destino a factores aleatorios o a la discrecionalidad de los militares. Pero lo que 
interesa aquí no es tanto la efectividad material de esa resistencia, sino el sentido que tuvo para esas mujeres.

Las mujeres embarazadas aparecen en el centro de la escena de muchos de los relatos sobre estas pequeñas resistencias y formas de solidaridad en el centro clandestino. Alicia Carminati rememora la actitud que tuvieron sus compañeros/as de encierro en el momento que Stella Ogando comenzó a tener contracciones:

Cuando Stella se descompone... cuando sucedía algo, alguno se mareaba o se desmayaba o, en el caso este, cuando Stella empezó con el trabajo de parto, todos empezamos a golpear la celda para que alguien subiera. Digamos que los golpes eran para llamar la atención. Normalmente, si golpeabas o no venían, o venían y te retaban o te castigaban por los golpes. El día que Stella empieza con contracciones, entonces, todos empezamos a golpear. Suben y la bajan a Stella. (Memoria Abierta, Testimonio de Alicia Carminati, 2006)

En diferentes pasajes del testimonio que citamos más arriba, Susana Reyes también planteaba la importancia que tuvo en su experiencia la solidaridad entre compañeras/ os. A pesar de las torturas y los maltratos, ella recuerda que "se iban fortaleciendo los lazos con mis compañeras, embarazadas quedábamos tres". En ese contexto, "el humor y el amor entre las compañeras te permiten vivir" -al menos durante el primero de los momentos que ella identifica en su relato.

En las distintas entrevistas pudimos ver que narrar esas formas de resistencia resulta sumamente revitalizante para muchas testimoniantes. Parece significar una resistencia en dos tiempos: por un lado, recordar ciertas acciones y calificarlas como "resistencias", si no habían sido formuladas como tales, es un acto reparador en sí mismo frente al poder deshumanizador; $y$, por otro lado, en los sucesivos presentes del testimonio se da una resistencia al silencio y a la impunidad, que al mismo tiempo permite reivindicar la humanidad de aquellas personas que ya no están, así como también la propia.

El testimoniar reviste múltiples sentidos para ellas. Algunas entrevistadas se refieren a su testimonio como una "responsabilidad", una "deuda" o un "privilegio". Esta voluntad de testimoniar está fuertemente asociada también con el anhelo de que la transmisión de la experiencia "sirva", que ayude a que se haga justicia, que contribuya a la memoria social del país, que aporte datos para conocer el destino de personas desaparecidas o apropiadas, que muestre los pequeños y grandes gestos que tejen la supervivencia y la solidaridad, y que provea cimientos para construir una sociedad mejor (Sutton, 2015). En este sentido, es muy claro el testimonio que Adriana Calvo brindó en el Juicio a las Juntas, en el que ella cuenta cómo las terribles condiciones de su parto la hicieran prometerse a sí misma que, si ella y su hija sobrevivían, dedicaría su vida a que se hiciera justicia:

El 15 de abril comenzó mi trabajo de parto alrededor de las 7 de la noche [...] era mi tercer hijo, ya sabía que iba a nacer muy rápido. Inés se quedó conmigo, y las demás comenzaron a llamar nuevamente al cabo de guardia [...] llegó un auto, un patrullero, me subieron al auto y salimos de la comisaría $5^{\text {a }}$ [...] iba acostada en el auto, vendada, los ojos vendados y con las manos atadas atrás, me dediqué, absolutamente todo el tiempo que duró el viaje, a decirles que yo me iba en libertad, que ellos me habían dicho que me largaban, que me llevaran a un hospital; ellos me dijeron que me llevaban a un hospital, me decían que sí, me decían sí a todo, me insultaban, les decía que estaba por nacer mi criatura, que no podía aguantar más; que pararan, que no era mi primer hijo, yo sabía que estaba por nacer [...] el que manejaba y el que lo acompañaba se reían, me decían que era 
lo mismo, que igual me iban a matar, iban a matar al chico, qué me importaba; por fin, yo no sé ni cómo alcancé a sacarme la ropa interior para que naciera, realmente no lo recuerdo; les grité, íbamos a toda velocidad por la ruta que une La Plata con Buenos Aires, iba el auto a toda velocidad, y yo les grité ya nace, no aguanto más, y efectivamente nació, nació mi beba. Pararon en la banquina [...]; mi beba nació bien, era muy chiquita, quedó colgando del cordón, se cayó del asiento, estaba en el piso, yo les pedía por favor que me la alcancen, que me la dejen tener conmigo, no me la alcanzaban, [...] mi beba lloraba, yo seguía con las manos atrás, seguía con los ojos tapados, no me la querían dar, señor presidente, ese día hice la promesa de que si mi beba vivía y yo vivía, iba a luchar todo el resto de mis días porque se hiciera justicia. (Testimonio de Adriana Calvo en el Juicio a las Juntas, 1985)

En los testimonios se advierte la importancia de ponerle palabras a la experiencia traumática en tanto las palabras dan sentidos que posibilitan el procesamiento del trauma (LaCapra, 2005). Y no solo como denuncia del horror, sino también como rescate de valores "cotidianos", como el cuidado de la compañera, el respeto y las distintas formas de resistencias. Recuperar estos relatos les devuelve a las sobrevivientes testimoniantes la agencia que pudieron tener en esos contextos de encierro. "Estas mujeres no quieren presentarse solo como víctimas. Los resquicios de resistencia a los que se refieren y las solidaridades que expresamente quieren reivindicar son fundamentales para entender cómo conviven con ese trauma procesando sus efectos pero sin paralizar sus vidas" (Bacci et al., 2012: 98).

\section{Conclusiones}

De manera similar a lo que ocurrió en otras dictaduras del Cono Sur de la época, la última dictadura militar argentina fue estructurada sobre patrones de género que valoraban el rol "tradicional" de la madre-esposa como cuidadora de las siguientes generaciones y, por tanto, del proyecto de Nación (Filc, 1997). Estas concepciones se anudaron en el mensaje que la dictadura militar se proponía dirigir a la ciudadanía: el reforzamiento de la institución familiar en su sentido occidental y cristiano. Siendo la familia la célula básica de la sociedad, allí se debía formar al "ser argentino" que tuviera los "anticuerpos" para combatir a los males inoculados por las organizaciones populares. La mujer debía cumplir un rol esencial siendo la garante de ese modelo en el ámbito privado (Andújar et al., 2009).

Este mismo constructo discursivo conservador atravesó, por supuesto, las prácticas represivas ejercidas por los agentes del Estado en distintos contextos: en la casa durante los allanamientos, en los centros clandestinos de detención y también en las cárceles. En cada uno de estos lugares se ejercieron violencias que tomaron, en muchos casos, formas generizadas y sexuadas. En los centros clandestinos de detención las mujeres fueron castigadas y torturadas no solo por su militancia social o política sino también por haber transgredido las fronteras aceptables de género y nación, según el discurso dictatorial.

Salvo excepciones, las mujeres embarazadas debieron sobrellevar sus embarazos en las mismas condiciones degradantes e insalubres que padecían todos/as los/as secuestrados/as en los centros clandestinos de detención, con los riesgos que eso suponía para su salud y la de sus hijos/as en gestación. Esa situación, como hemos visto, marcó fuertemente la experiencia de sus secuestros y cautiverios. 
Como expusimos, se dieron situaciones diversas. En muchos casos, las mujeres embarazadas fueron sometidas a una instrumentalización de su cuerpo en espacios diferenciados (las "maternidades") con el objeto de apropiarse de sus hijos/as. En estos casos, tras consumarse la apropiación, casi todas fueron "trasladadas", es decir, asesinadas. La puesta en marcha de la apropiación supuso el despliegue de estrategias y dispositivos represivos específicos para el control de los cuerpos de las mujeres embarazadas y la sustracción, entrega y "legalización" de sus hijos/as nacidos/as en cautiverio. Para el desarrollo de esas estrategias y dispositivos fue indispensable la colaboración de distintos agentes e instituciones de la burocracia estatal y del campo de la salud (Villalta, 2012; Regueiro, 2013).

Asimismo, hubo mujeres que estuvieron embarazadas en cautiverio y que fueron liberadas poco antes de parir e, incluso, en algunos pocos casos, sus hijos/as fueron entregados/as a sus familias, permaneciendo ellas detenidas (como le sucedió a Marta Álvarez). Por una cuestión de extensión no hemos profundizado en las situaciones que atravesaron las mujeres que parieron en libertad habiendo pasado su embarazo en cautiverio, pero hemos retomado algunos testimonios en los que ellas narran cómo el cautiverio marcó sus experiencias de maternidad posteriores.

En su clásica obra Of Woman Born..., la poeta, crítica y activista feminista Adrianne Rich establece una importante distinción entre dos acepciones de la "maternidad": la maternidad como experiencia intrínsecamente femenina ("mothering"), definida por el "vínculo potencial de toda mujer con sus fuerzas reproductivas y sus hijos/as", y la maternidad como institución patriarcal ("motherhood"), que tiene como objetivo "asegurar que ese potencial y todas las mujeres permanezcan bajo control masculino" (Rich, 1995: 13). Esta distinción permite percibir la maternidad en su doble faz de constructo cultural e imperativo social, pero también de experiencia corporal singular que atraviesan las mujeres. Es la maternidad como institución patriarcal la que oprime a las mujeres y refuerza la estructura jerárquica de géneros. Por el contrario, la maternidad entendida como mothering es una experiencia definida y controlada por las mujeres y que potencialmente puede empoderarlas.

La conceptualización elaborada por Rich resulta útil para pensar la actitud (solo en apariencia contradictoria) de los represores, que por un lado apelaban a un discurso que pretendía revalorizar el lugar de la mujer como "madre y esposa occidental y cristiana", pero, al mismo tiempo, no mostraban reparos en someter a las detenidas embarazadas a humillaciones, torturas, vejaciones y asesinatos. Lo que interesaba a los represores no era la suerte corrida por las experiencias maternales concretas y reales de esas mujeres que, en tanto "subversivas", habían sido degradadas simbólica y materialmente, sino reforzar la maternidad como institución patriarcal, como elemento estructurante de las relaciones jerárquicas de género que habían sido puestas en tensión. Más aún, la distinción conceptual entre la maternidad como institución y como experiencia nos permite acercarnos a la comprensión de los sentidos que estas mujeres le otorgaron a sus vivencias de embarazo y maternidad en cautiverio, sentidos que iban mucho más allá de lo que decían, hacían y pretendían los agentes del poder concentracionario.

A partir de los testimonios seleccionados pretendimos dar cuenta de las experiencias y los sentidos de las maternidades atravesadas por el poder concentracionario. Más allá de la diversidad de las situaciones, tanto las mujeres que habían sido madres antes de ser secuestradas, las que estuvieron embarazadas durante su secuestro y parieron en libertad como las que parieron en el centro clandestino y sobrevivieron narran que la maternidad marcó especialmente su cautiverio y, al mismo tiempo, este incidió significativamente en su experiencia maternal. 
Por último, hemos visto en los distintos testimonios que para las mujeres sobrevivientes es muy importante simbolizar las experiencias traumáticas. Narrar lo vivido $-\mathrm{y}$ especialmente narrar las resistencias y solidaridades que se dieron en el contexto concentracionario- es también para ellas una forma, a posteriori, de resistir y, así, de enfrentar la impunidad y el silencio. 


\section{Bibliografía}

Águila, G. (2013). La represión en la historia reciente argentina: fases, dispositivos y dinámicas regionales. En Águila, G. y Alonso, L. (coords.) Procesos represivos y actitudes sociales: entre la España franquista y las dictaduras del Cono Sur. Buenos Aires, Prometeo Libros.

»Álvarez, V. (2000). El encierro en los campos de concentración. En Gil Lozano, F.; Pita, V. e Ini, M. G. Historia de las mujeres en la Argentina. Tomo II: Siglo XX. Buenos Aires, Taurus.

»----- (2015). Género y violencia: Memorias de la represión sobre los cuerpos de las mujeres durante la última dictadura militar argentina. En Nomadías. Revista de estudios de género de Chile, 15.

»Andújar, A.; D’Antonio, D.; Domínguez, N.; Grammático, K.; Gil Lozano, F.; Pita, V.; Rodríguez, M. I. y Vasasallo, A. (comps.) (2009). Historia, género y política en los $\bigotimes_{70}$. Buenos Aires, Feminaria Editora.

" Aucía, A.; Barrera, F.; Berterame, C.; Chiarotti, S.; Paolini, A. y Zurutuza, C. (2011). Grietas en el silencio. Rosario, CLADEM (Comité de América Latina y el Caribe para la Defensa de los Derechos de las Mujeres e INSGENAR (Instituto de Género, Derecho y Desarrollo).

»Bacci, C.; Capurro Robles, M.: Oberti, A. y Skura, S. (2012). $\nabla Y$ nadie quería saber冈. Relatos sobre violencia contra las mujeres durante el terrorismo de Estado en Argentina. Buenos Aires, Memoria Abierta.

»Barrancos, D. (2008). Mujeres, entre la casa y la plaza. Buenos Aires, Sudamericana.

"Calveiro, P. (1998). Poder y desaparición. Los campos de concentración en Argentina. Buenos Aires, Colihue.

"Cosse, I. (2010). Pareja, sexualidad y familia en los años sesenta: una revolución discreta en Buenos Aires. Buenos Aires, Siglo XXI.

"D’Antonio, D. (2016). La prisión política en los años 70. Historia, género y política. Buenos Aires, Biblos.

"Domínguez, N. (2007). De dónde vienen los niños. Maternidad y escritura en la cultura argentina. Rosario, Beatriz Viterbo.

»Duhalde, E. L. (1999 [1983]). El estado terrorista argentino. Buenos Aires, Eudeba.

»Filc, J. (1997). Entre el parentesco y la política. Familia y dictadura, 1976-1983. Buenos Aires, Biblos.

» Franco, M. (2012). Un enemigo para la nación. Orden interno, violencia y "subversión", 1973-1976. Buenos Aires, FCE.

"LaCapra, D. (2005). Escribir la historia, escribir el trauma. Buenos Aires, Nueva Visión.

"Lagarde, M. (1997). Los cautiverios de las mujeres: madresposas, monjas, putas, presas y locas. México, UNAM.

» Nosiglia, J. (1985). Botín de guerra. Buenos Aires, Tierra Fértil.

"Oberti, A. (2015). Las revolucionarias. Militancia, vida cotidiana y afectividad en los 
setenta. Buenos Aires, Edhasa.

»Pittaluga, R. (2010). El pasado reciente argentino: Interrogaciones en torno a dos problemáticas. En Bohoslavsky, E.; Franco, M.; Iglesias, M. y Lvovich, D. Problemas de historia reciente del cono sur. Buenos Aires, Prometeo/UNGS.

"Regueiro, S. (2013). Apropiación de niños, familias y justicia. Argentina (1976-2012). Rosario, Prohistoria.

» Rich, A. (1995). Of Woman Born: Motherhood as Experience and Institution. Nueva York, WW Norton \& Company.

»Segato, R. (2003). Las estructuras elementales de la violencia. Contrato y status en la etiología de la violencia. Brasilia, Serie Antropológica 334.

»Sonderéguer, M. (2012). Género y poder. Violencias de género en contextos de represión política y conflictos armados. Bernal, Universidad Nacional de Quilmes.

"Sutton, B. (2015). Terror, testimonio, y transmisión: Voces de mujeres sobrevivientes de centros clandestinos de detención en Argentina (1976-1983). En Mora, vol. 21 núm. 1. Buenos Aires.

»Villalta, C. (2012). Entregas y secuestros. El rol del Estado en la apropiación de niños. Buenos Aires, Del Puerto.

\section{Otras fuentes consultadas}

\section{Testimonios}

»Entrevista a Ana María Careaga realizada por Lizel Tornay, Victoria Álvarez y Fernando Álvarez para el documental Campo de batalla. Cuerpo de mujer. Octubre de 2011, Buenos Aires.

»Entrevista a Charo Moreno realizada por Lizel Tornay, Victoria Álvarez y Fernando Álvarez para el documental Campo de batalla. Cuerpo de mujer. Abril de 2012, Buenos Aires.

"Entrevista a Isabel Cerruti realizada por Lizel Tornay, Victoria Álvarez y Fernando Álvarez para el documental Campo de batalla. Cuerpo de mujer. Abril de 2012, Buenos Aires.

"Entrevista a Miriam Lewin realizada por Lizel Tornay, Victoria Álvarez y Fernando Álvarez para el documental Campo de batalla. Cuerpo de mujer. Mayo de 2012, Buenos Aires.

» Juicio a las Juntas. Testimonio de Adriana Calvo, Buenos Aires, 1985.

» Juicio a las Juntas. Testimonio de Elena Alfaro, Buenos Aires,1985.

"Memoria Abierta. Testimonio de Alicia Carminati, Buenos Aires, 2006.

"Memoria Abierta. Testimonio de Delia Bisutti, Buenos Aires, 2001.

" Memoria Abierta. Testimonio de Marta Álvarez, Buenos Aires, 2007.

》Memoria Abierta. Testimonio de Susana Reyes, Buenos Aires, 2003. 
